\title{
Academic staff perspectives on technology for assessment (TfA) in higher education: a systematic literature review.
}

Mairead Brady, Ann Devitt and Rachel A. Kiersey

Address for correspondence: Mairead Brady, Trinity Business School, Trinity College Dublin, College Green, Dublin 2, Ireland.

Email: Mairead.Brady@tcd.ie

Mairead Brady is an Assistant Professor of Business at the Trinity Business School, Trinity College Dublin. Her research investigates academic staff and student technological adoption within the higher education setting, with a particular focus on simulations and social media applications.

Ann Devitt is an Assistant Professor of Modern Languages at the School of Education in Trinity College Dublin. Ann's research interests lie in the area of language teaching and learning, and technology enhanced learning.

Rachel A. Kiersey is a research fellow in Trinity College Dublin interested in qualitative research, particularly qualitative methodology, discourse analysis, and systematic reviews for evidence-based research. 


\begin{abstract}
This paper presents a systematic literature review of academic staff experiences and perceptions of adopting Technology for Assessment OF/FOR/AS Learning in Higher Education. This article is a qualitative synthesis of 65 peer-reviewed journal articles published between 2012 and 2017 reporting on the use of technology for assessment (TfA). The results suggest that there are some efficiencies for staff in implementing TfA but this can come with a cost at the set-up and maintenance phases. Furthermore, results indicated that assessment design is not of foremost concern to academic staff when introducing TfA, but that a wide variety of pressures and both educational and operational drivers are present. There were inconclusive findings in relation to understandings of appropriate institutional environments and supports for TfA to flourish in higher education. There is a need for empirical research, particularly longitudinal investigations, of academic experiences of implementations of TfA to investigate sustainability of adoption. The imperative of exploring the academic staff perspective as the instigator and manager of both the technology and the student learning experience requires deep consideration as TfA adoption progresses.
\end{abstract}

\title{
Practitioner Notes
}

What is already known about this topic?

- Technology offers the potential to add value to the assessment process in higher education.

- There is a plenty of research on student experiences and perspectives on TfA but comparatively little empirical data on TfA implications for academic staff in higher education.

- The development, design and use of Technology for Assessment (TfA) should be underpinned by considered and relevant pedagogy and educational theory to enhance the assessment process.

What this paper adds:

- Technology is most often adopted for formative, low-stakes assessment rather than summative Assessment of Learning.

- Integration of technology use into the overall pedagogic framework was not explicitly considered when introducing TfA.

- The impact on academic staff workload ranged from positive to negative depending on the specific assessment design and the technology usage.

- It is not clear which institutional environments best supports the adoption of technology for assessment.

Implications for practice and/or policy:

- Practitioners should deploy technology as an integral part of their educational design rather than as an afterthought or a quick fix solution to specific problems. 
- The resources implications in terms of staff time and effort for both planning and operating TfA should be carefully considered.

- In the context of rapid technological change and innovation, institutions should align the technological and operational supports they make available to the specific educational needs of staff and students.

- To develop evidence based policies there is a need for a broader base of focused empirical investigations on the educational efficacy, the resource implications, and staff experiences of specific technology usage.

\section{Introduction}

As technology becomes ever more pervasive in society, the role and influence of technology is under review or even intense scrutiny. In education, while the range of technologies available for teaching, learning and assessment continue to grow, the adoption of technology by academic staff, in particular for assessment, is not uniform or sustained (Bennett, Dawson, Bearman, Molloy, \& Boud, 2017; Spector, Ifenthaler, Samspon, Yang, Mukama \&Warusavitarana, 2016). This systematic literature review explores the perspectives and experiences of academic staff utilising technology within assessment OF/FOR/AS learning, specifically in the higher education sector.

Despite a growing number of studies into technological adoption within teaching and learning in higher education (Habib \& Johannesen, 2014; King \& Boyatt, 2015; Paiva, Morais, Costa, \& Pinheiro, 2017) there is a need for more studies that consider academic staff's technology and assessment utilisation (Bennett, et al., 2017; Deeley, 2018). Studies which focus on students and technology and assessment prevail including a critical emphasis on the student voice within digital technology use (Manca, Grion, Armellini, \& Devecchi, 2017). Examining the experiences of staff that are responsible for the design and implementation of technology for assessment is also an essential perspective (Bennett et al., 2017; Kirkwood \& Price, 2013; Paiva et al., 2017). but there is a noted scarcity of studies thoroughly investigating many of the core issues critical to academic staff (Fung \& Gordon, 2016).

Throughout the paper, we use the term academic staff to refer to staff with direct responsibility for teaching learning and assessment activities.

\section{Assessment OF/FOR/AS Learning}

Assessment is a critical process in education, constituting a site for both measuring and supporting student learning. This systematic review distinguishes assessment as:

- Assessment OF Learning (AoL): summative assessment, takes place after a cycle of learning and measures what has been learnt. Information is gathered external to the learner (e.g. by a teacher or examiner) (Black, 2008; Earl, 2013).

- Assessment FOR Learning (AfL): formative assessment, is integral to the learning process, happens throughout the cycle of learning; gathers evidence of learning to support and progress learning by both the teacher and the learner, and shared with the learner (Black, Harrison, Lee, Marshall, \& Wiliam, 2004).

- Assessment AS Learning (AaL): a component of AfL concerned with the student role within assessment, focuses on engaging the student as an active agent in the assessment 
process, setting success criteria, peer and self-assessing, using activities and feedback to progress their learning (Earl, 2013).

These three dimensions of assessment are not mutually exclusive, for example formative feedback can be provided on a summative task (AoL and AfL) or students can be graded on their interpretation and use of prior feedback (Aol and AaL). Each paper in the systematic literature review was interrogated and categorised as to whether it addresses AoL, AfL, AaL or a combination thereof.

This study expands on other reviews that emphasised the perceptions of academic staff (Heitink, Van der Kleij, Veldkamp, Schildkamp, \& Kippers, 2016) by taking a wider perspective on assessment to include formative and summative assessment. It also explores a wide range of technologies (see table 2) used by academic staff within assessment in the HE sector.

\section{Technology for Assessment (TfA)}

Given the range of technologies available, the affordances of technology for assessment are many and varied, offering for example opportunities for experiential learning, collaborative learning, and speedy or instant feedback (Daly, Pachler, Mor and Mellar, 2010; Spector et al., 2016). Technology Enhanced Assessment (TEA) has been defined as the "use of technology to extend or add value to assessment and feedback processes" (JISC, 2010, p. 57). Nonetheless, there is some contention around the use of the term TEA to discuss all uses of technology in the assessment process. Selwyn (2013) highlights a preference for the use of the term digital technologies for learning rather than technology enhanced learning which he cites as a term full of presumptions. Similarly, Dawson and Henderson (2017) understand the term TEA as implying that technology can or does enhance education and the assessment process. While the JISC definition, does not comment on where TEA is effectively underpinned by educational theory and pedagogy, the broader discussion of TEA would suggest that it should align with effective, valid and reliable assessment practices (JISC, 2010; Sweeney et al., 2017). As such it is a value laden term which may promote a positive bias and lacks critique of technology adoption for assessment purposes. Therefore, this systematic literature review proposes the unbiased term Technology for Assessment (TfA) to provide a necessary critique of research, policy and practice.

\section{Research Questions}

The majority of papers in this domain tend to weigh heavily on how TfA impacts on and affects students, with a lack of explicit research from the perspective of academic staff as they operationalize technology for assessment. The aim of this systematic review was to explore academic staff experiences and perceptions of adopting technology for Assessment OF/FOR/AS Learning in Higher Education, addressing the following qualitative research questions:

1. What models of assessment design can assist academic staff to harness the potential of technology to enhance student learning? 
2. How can technology enhance academic staff efficiencies in the Assessment OF/FOR/AS Learning process?

3. What types of environment and support do institutions need to provide to encourage technology enhanced (i.e. pedagogically grounded) Assessment OF/FOR/AS Learning?

\section{Systematic Literature Review Methods}

To systematically review the literature is to ensure a rigorous and accountable approach to searching and critical analyses (Gough, Oliver, \& Thomas, 2012; Higgins \& Green, 2011). The goal was to identify studies that explored academic staff experiences of technology for assessment (TfA). The systematic search took a broad perspective on technologies used for assessment (TfA) while concentrating on the following specific technology areas as a guideline to inform the search terminology:

\section{Virtual Learning Environment (VLE) \\ Games and Simulations \\ Web 2.0-Social Media \\ Interactive Multimedia Environments \\ Intelligent Tutorial Systems (ITS) \\ Webinars-Podcasts - video \\ MOOCS-Distance-Open Source \\ Multiple Technologies}

The review followed the style of a Cochrane systematic review (Higgins \& Green, 2011) and included a qualitative synthesis of answers to the research questions. The Cochrane

recommended tool EPPI Reviewer (EPPI Centre, 2017) was used as it provides appropriate tools to undertake the systematic literature review and qualitative synthesis concurrently.

\section{Search strategy}

The search was carried out across the following databases.

1. Academic Search Complete (EBSCO hosted)

2. PsycInfo (EBSCO hosted)

3. ERIC (ProQuest hosted; subject specific thesaurus)

4. Scopus (subject specific thesaurus)

Search terminology were developed over several iterations for a long-form search string to carry out long-form searches in two of the databases, hosted by EBSCO, see figure 1. Keywords were trialled and subsequently added or removed from the string in an iterative process. For example the keyword "mobile" did not add any additional pertinent results, so m-, smart* iPad* were used as they proved to retrieve pertinent results. 


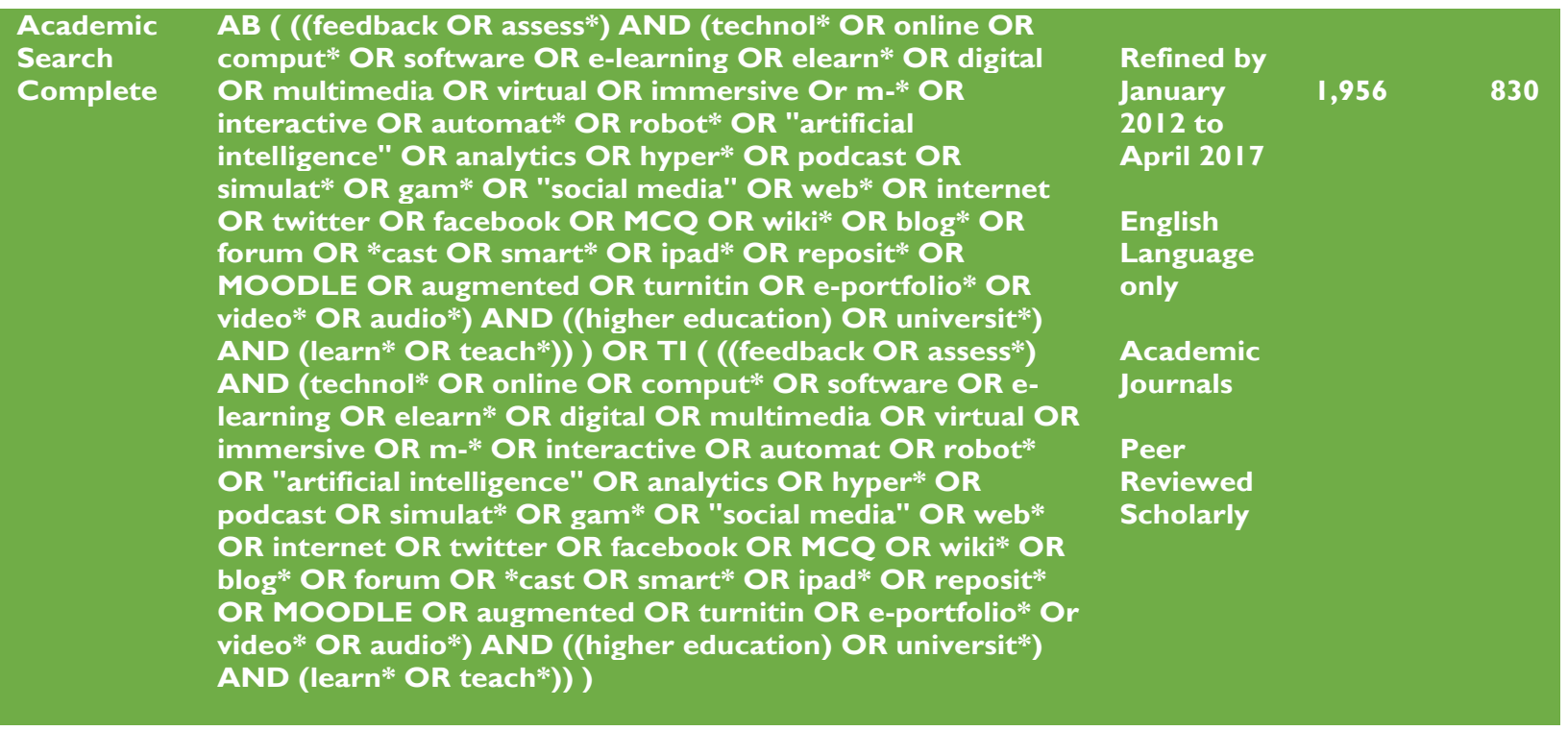

Figure 1 Example of full long-form search string used in EBSCO hosted databases

The ProQuest hosted ERIC database contains a subject specific thesaurus rather than allowing a long-form string search such as for EBSCO. Therefore, this was used to execute the search, as in figure 2 below. Similarly, there is a subject specific thesaurus on Scopus which was also used.

$\begin{array}{ll}\text { ERIC } & ((((((\text { technol* AND ((higher education) OR universit*)) AND } \\ \text { Search } & \text { schol(yes) AND peer(yes) AND la.exact("English") AND } \\ \text { IV("postsecondary education" OR "higher education")) AND } \\ \text { SU.EXACT.EXPLODE("Assignments") AND } \\ \text { SU.EXACT.EXPLODE("Educational Technology") NOT } \\ \text { (SU.EXACT.EXPLODE("EVALUATION") OR feedback* OR } \\ \text { assess*) AND la.exact("English") AND IV("postsecondary } \\ \text { education" OR "higher education")) AND rtype.exact("080 } \\ \text { Journal Articles") AND pd(>20I00I0I)) AND } \\ \text { rtype.exact("080 Journal Articles")) AND schol(yes)) AND } \\ \text { peer(yes)) AND rtype.exact("080 Journal Articles") AND } \\ \text { pd(>20I00I0I) }\end{array}$

Figure 2 Example of subject thesaurus search in ProQuest hosted database

\section{Inclusion/Exclusion Criteria}

\section{Table 1 Inclusion/Exclusion Criteria}

\begin{tabular}{|ll|}
\hline Inclusion & Exclusion \\
\hline Published after 2012 & Published before 2012 \\
\hline English language & Not English language \\
\hline From selected ranked/subject specific journals & From non-relevant journals \\
\hline Peer reviewed & Grey literature/Not peer reviewed \\
\hline Explicitly addresses some type of TfA & Does not cover explicit TfA \\
\hline Examines views of higher education academic & Study of students only \\
\hline
\end{tabular}


staff not solely students

Answers all or some elements of research questions

Does not contribute anything to answer research questions

\section{Screening}

The refined results of the search were imported into EndNote and EPPI Reviewer for the screening process, see figure 3 . The first phase of screening involved all three authors screening the same sample of $10 \%$ of the references by title and abstract to include and exclude papers based on their relevance to the research goals. Following the sample screening, the three authors reconciled any disagreements, agreed parameters for operationalising the inclusion/exclusion criteria (see table 1) and distributed the remaining papers for title and abstract screening. After this phase, and to further strengthen inter-rater reliability the authors discussed, disputed, and reconciled the final results and allocated the remaining papers by technology topic for full text screening.

The full text screening phase involved reading each paper thoroughly to discern its suitability based on whether it met the inclusion criteria, was evaluated to be of suitable quality, and answered some or all of the research questions. Following screening author 3 reviewed and queried all screening assessments through moderating discussion with authors 1 and 2 until consensus was reached on all inclusions; this was done to strengthen inter-rater reliability and bolster the quality of the systematic review. 


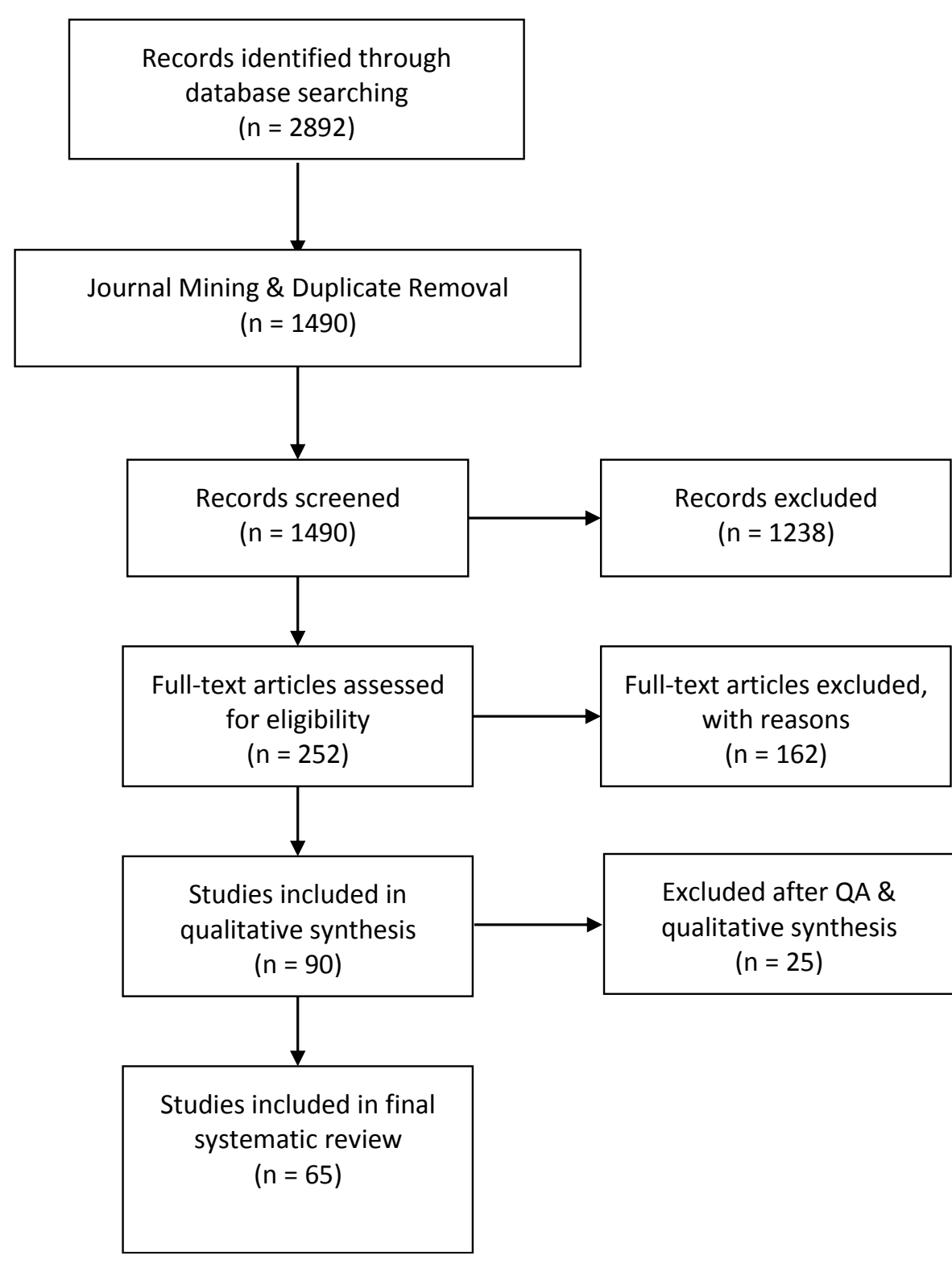

Figure 3 Search, retrieval and screening flowchart (modified from Moher, Liberati, Tetzlaff, \& Altman, 2009)

\section{Quality appraisal}

Search results were refined to high ranked journals only as per the inclusion criteria, see Table 1. A quality assessment (QA) was undertaken on all papers that underwent full text screening by the reviewers, to ensure that only the most trustworthy and pertinent studies are included in the final review (Harden \& Gough, 2012). Three QA tools were used to address the three different 
types of papers included in the systematic review: qualitative; quantitative; and review papers. The QA tools ask questions pertaining to assessing the methods and rigour of each paper and correspondingly assign a rating from 1-strong to 3-weak; these questions are included in supplementary information to this paper (S2). The three tools were:

1. QA tool for qualitative papers (Keane, Sutton, Farragher, \& Long, 2016);

2. QA tool which is standard in EPPI Reviewer for quantitative papers (EPPI Centre, 2017);

3. QA tool for review papers, including systematic review (McMaster University, 2016).

The review is composed mainly of moderate papers (figure 4). Excluded papers did not address the qualitative research questions, did not include an academic staff perspective, or were deemed to be weak papers with no relevant evidence.

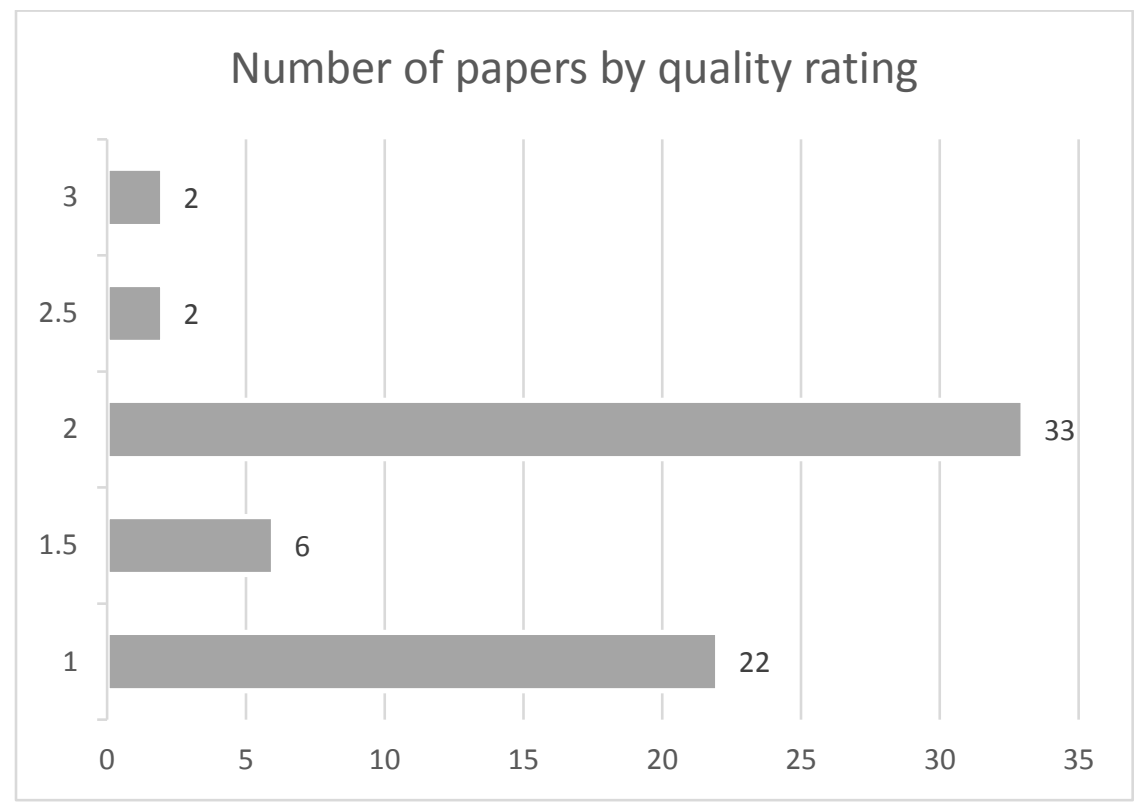

Figure 4 Number of papers by quality rating.

\section{Data Extraction and Analysis}

Data extraction and analysis was carried out using EPPI Reviewer (EPPI Centre, 2017). Thematic analysis was undertaken across the papers using the relevant information that had purported to answer the research questions. Further descriptive analysis was undertaken to build a narrative telling the story of how TfA, as discussed in each paper, impacted on each of the research question areas from an academic staff perspective: models of assessment design, academic staff efficiencies, and institutional environment and support.

\section{Findings from the Systematic Review}

This section provides an overview of the study characteristics of the 65 papers followed by a synthesis of the findings under the three research questions. The 65 studies were distributed across quantitative (20 papers), mixed methods (16 papers) and qualitative or narrative studies 
(27 papers) with 2 review papers included. The papers used a wide range of data collection methods or combinations thereof, including interviews, questionnaires, outcome testing, etc. The number of staff participants in the studies varies greatly ranging from under 10 to 400 . The majority of studies were in the range of 10-30 participants. The largest qualitative academic staff sample is the Bennett et al. (2017) paper with 33 participants. Several studies about automated assessment did not include any human participants but rather evaluated the system relative to a gold standard of evaluations. In these studies, the "academic staff" perspective is provided by the effectiveness and reliability of the software.

The articulation of drivers for adoption of TfA in the papers was also explored: 30 studies situated the introduction of TfA tools as an individual, faculty or departmental decision; 17 papers situated it as an institutional decision; 17 papers were unclear or had no pertinent information, and one paper (Link et al., 2014) was research project led. Detailed information about each paper is provided as Supplementary Information (Table S1). Many papers reported on early adopters or innovators mainly trialling technologies and applications of technology rather than widespread pedagogically oriented assessment redesign through TfA. Therefore, though of interest and value there was little or no interrogation of the TfA tool beyond staff's own motivations, interests and perspectives of the pros and cons for the TfA introduction and use. Papers looking at multiple adopters/implementers of TfA were limited to four main studies with varying adoption patterns and no single technological focus (Bennett et al., 2017; Gray et al., 2012; McNeill, Gosper, \& Xu, 2012; Waycott, Sheard, Thompson, \& Clerehan, 2013). Other studies showed evidence of limited adoption predominantly in the first year of use (Mettiäinen, 2015; Tao, Cheng, \& Sun, 2012).

\section{Assessment Design}

What models of assessment design can assist academic staff to harness the potential of technology to enhance student learning?

The studies examined for this systematic review tended not to consider models of assessment design in an explicitly theoretically defined paradigm which was a barrier to directly answering the research question. In many cases assessment design was not discussed or nameda.

Nevertheless, aspects that can underpin assessment design were touched upon in different contexts throughout the papers.

Using theory to situate and frame a paper can demonstrate a considered approach to study design and can often incorporate some insight into approaches to assessment design. In the papers that did address some consideration of assessment design, we examined if and how theoretical frameworks were applied to the study, and the relationship between them and technology topics. Also, of importance was how studies addressed Assessment OF/FOR/AS Learning, if they did at all, and how this integrated with the pedagogical underpinnings of the paper (if stated) and the goals of the study. 


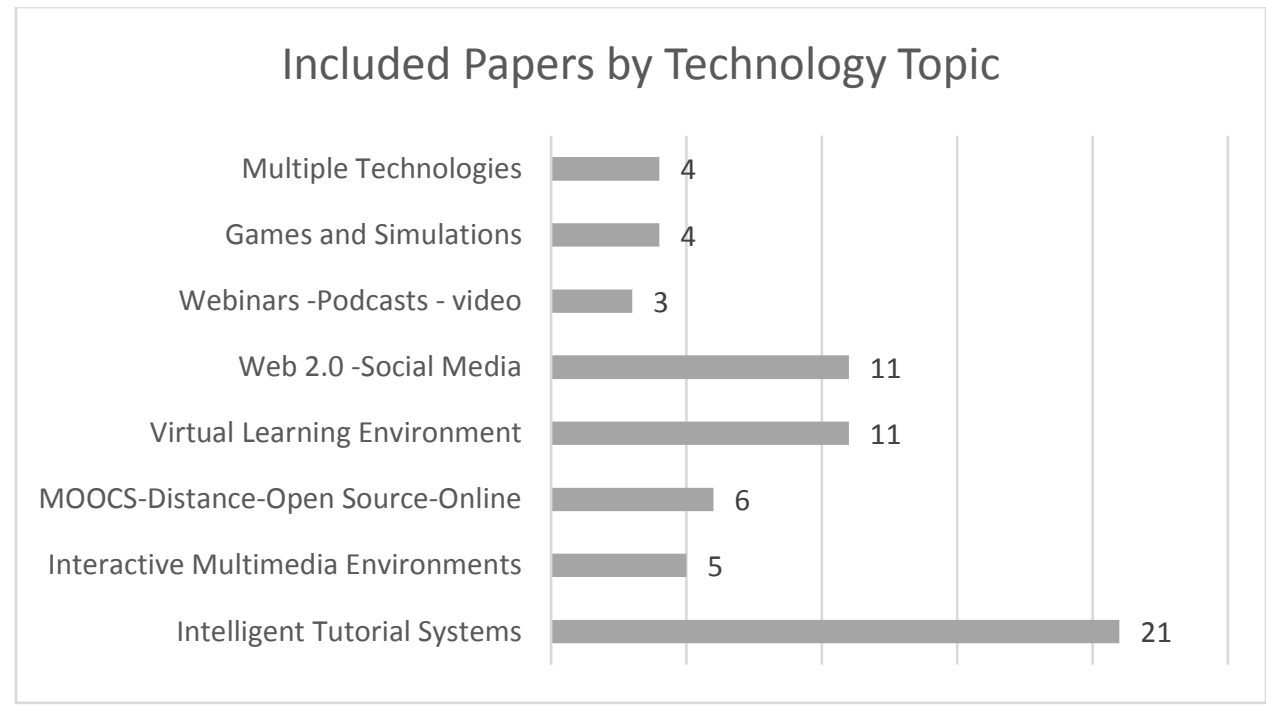

Figure 2 Number of papers by technology topic

\section{Theoretical frameworks and technology topics}

Papers about intelligent tutorial systems (ITS) were the most frequent in the included papers for review, see figure 5, yet only 3 of these papers included a theoretical framework. A total of 25 papers in the systematic review had a theoretical framework. The technology topics with the strongest relationship to theoretical frameworks were Web 2.0-Social Media with 6 from 11 papers, and Games and Simulations where all 4 papers included a theoretical framework (see table S1).

In several papers, including Cochrane, Sissons, Mulrennan, and Pamatatau (2013), theoretical frameworks are named without a demonstrable link between theory and practice or the study design and findings. Conversely, Rubin, Fernandes, and Avgerinou (2013), a study on integrating a VLE, lists and synthesises two theoretical frameworks, constructivism and affordance theory and clearly demonstrates how the theory informs the study design and findings. Similarly in Blackburn (2017), Problem-Based Learning (PBL) and Communities of Practice are named as theoretical frameworks, interrelated, and evidently inform the study design and discussion. Papers that incorporated Bloom's taxonomy also clearly demonstrated links between study design, use of the TfA, and outcomes. Table 2 below displays theoretical frameworks that were named in individual papers.

Table 2 Theoretical frameworks included in the studies

\begin{tabular}{|ll|}
\hline Theoretical framework & Studies \\
\hline Affordance Theory & Haines (2015); Rubin et al (2013). \\
\hline Authentic Assessment & Neely \& Tucker (2013). \\
\hline Bloom's Taxonomy & $\begin{array}{l}\text { Chao et al (2012); McNeill et al (2012); } \\
\text { Schaffer et al (2017); Sullivan (2016); Sun et } \\
\text { al (2014). }\end{array}$ \\
\hline Communities of Practice & Blackburn (2017); Cochrane et al (2013). \\
\hline
\end{tabular}




\begin{tabular}{ll}
$\begin{array}{ll}\text { Constructivist; Social constructivist } \\
\text { (Vygotsky) }\end{array}$ & $\begin{array}{l}\text { Çakiroglu et al (2016); Chen et al (2013); } \\
\text { Cochrane et al (2013); Goldstein \& Peled } \\
\text { (2016); Hutchings \& Quinney (2015); Link }\end{array}$ \\
& $\begin{array}{l}\text { (2014); Onrubia \& Engel (2012); Pittenger \& } \\
\text { Olson-Kellogg (2012); Rubin et al (2013); }\end{array}$ \\
& Wimpenny (2012); Zheng et al (2015). \\
\hline $\begin{array}{l}\text { Laurillard's conversational framework } \\
\text { Problem-based Learning theories }\end{array}$ & Almpanis (2015) \\
\hline Technology Acceptance Model (TAM) & $\begin{array}{l}\text { Caminero et al (2016); Schoonenboom } \\
\text { (2012); Tao et al (2012). }\end{array}$ \\
$\begin{array}{l}\text { Technological Pedagogical and Content } \\
\text { Knowledge (TPACK) }\end{array}$ & Sweeney (2017). \\
\hline
\end{tabular}

\section{Pedagogical underpinnings and Assessment OF/FOR/AS Learning}

Some of the studies with pedagogical underpinnings focusing on structured well-scaffolded tasks were also concerned with developing skills for self-assessment to advance Assessment AS Learning (Table 3). Less than half of the studies, which looked at fostering collaborative learning, were situated as explicitly considering or discussing the Aol/AfL/AaL concepts of assessment as integrated with their pedagogical goals. Studies, which looked at developing selfreflective skills, through feedback as a pedagogical underpinning, tended to align with developing Assessment FOR and AS Learning, with AfL being the more prominently named of the two. This potentially reinforces the implicit understanding of AaL as a part of AfL.

Table 3 Pedagogical Underpinnings in the studies

\begin{tabular}{|c|c|}
\hline Pedagogical Underpinnings & Studies \\
\hline $\begin{array}{l}\text { Structured well-scaffolded tasks } \\
\text { - freeing up class-time } \\
\text { - promoting interactive or self-directed } \\
\text { learning }\end{array}$ & $\begin{array}{l}\text { Bennett et al. (2017); Blackburn (2017); } \\
\text { Çakiroglu, Kokoç, Kol, and Turan (2016); } \\
\text { Caminero et al. (2016); Chao, Hung, and } \\
\text { Chen (2012); Flosason, McGee, and Diener- } \\
\text { Ludwig (2015); Liou, Bhagat, and Chang } \\
\text { (2016); Maher et al. (2013); Neely and } \\
\text { Tucker (2013); Sullivan (2016); Summers, } \\
\text { Robinson, and Timmons (2014); Sun et al } \\
\text { (2014); Sweeney et al. (2017); Tao et al. } \\
\text { (2012). }\end{array}$ \\
\hline $\begin{array}{l}\text { Fostering collaborative learning } \\
\text { - often through Web 2.0-Social Media tools }\end{array}$ & $\begin{array}{l}\text { Blair, Maharaj, and Primus (2016); Çakiroglu } \\
\text { et al. (2016); Caple and Bogle (2013); } \\
\text { Goldstein and Peled (2016); Gray et al. } \\
\text { (2012); Haines (2015); Lafuente Martínez, } \\
\text { Álvarez Valdivia, and Remesal Ortiz (2015); } \\
\text { Onrubia and Engel (2012); Pittenger and } \\
\text { Olson-Kellogg (2012); Waycott et al. (2013); }\end{array}$ \\
\hline
\end{tabular}


Developing self-reflective/self-directed skills
Zheng, Niiya, and Warschauer (2015).

Chen, Wei, Huang, and Kinshuk (2013);

Cochrane et al. (2013); Crook et al. (2012);

Liou et al. (2016); McNeill et al. (2012);

Mettiäinen (2015); Whitelock, Thorpe, and Galley (2015)

Out of all the studies reviewed, 45 out of 65 papers explicitly addressed, named or contextualised Assessment OF/FOR/AS Learning; 10 out of the 45 papers addressed all three in some respect. The graphic in figure 6 shows the breakdown of each of Assessment OF/FOR/AS Learning as they were addressed across the 45 papers. Developing AfL was the most dominant approach related to the design, implementation, or examination of TfA.

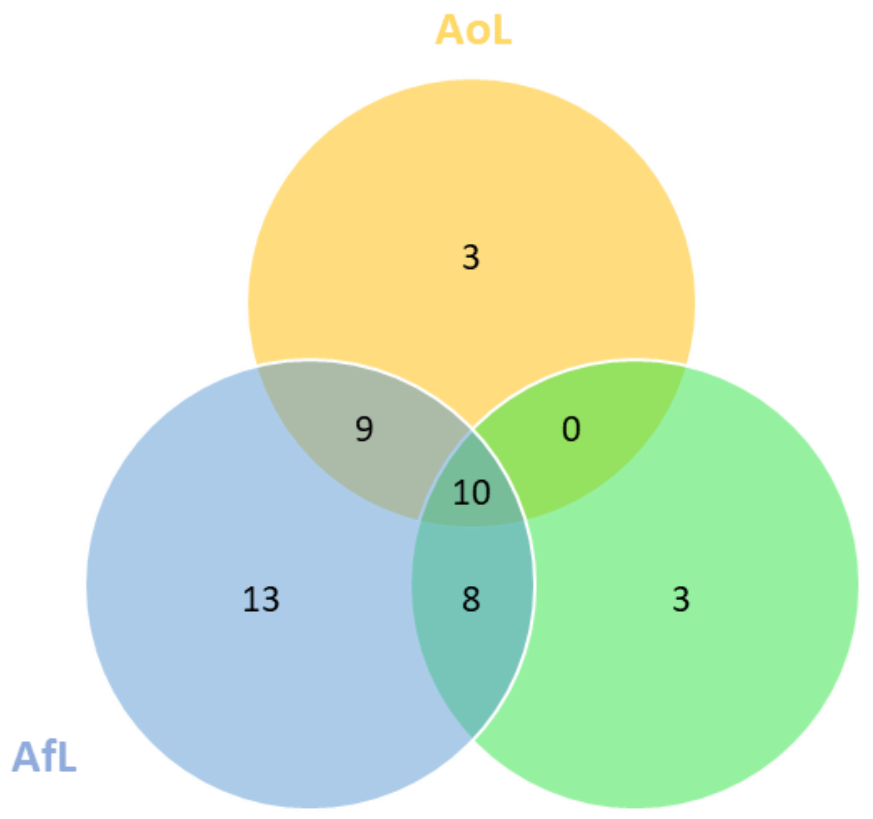

Figure 3 Number of papers that address one or more of Assessment OF/FOR/AS Learning.

\section{Summary}

The available findings did not explicitly answer what models of assessment design can assist academic staff to harness the potential of technology to enhance student learning. However, studies that included explicit theoretical frameworks and pedagogical underpinnings typically demonstrated a stronger understanding of assessment design.

\section{Academic Staff Efficiencies}

How can technology enhance academic staff efficiencies in the Assessment OF/FOR/AS

Learning process?

Approximately half of the studies reviewed were concerned with facets of efficiencies for academic staff from TfA use. These studies were exploratory and qualitative with no study 
showing the statistical significance, in terms of for example time saved, of their findings. There were mixed findings with some TfA (intelligent tutorial systems) demonstrating enhanced aspects of academic staff efficiencies, predominantly in relation to time saving and workload reduction. Others demonstrated increased and often overwhelming workloads (Web 2.0-Social Media) but with perceived educational advantages. Unfortunately and critically there was a lack of explicit statements of time saved, or limited indications of time and resources needed to set up and manage any of the TfA discussed. Some studies considered unexpected consequences and workloads (McNeill et al., 2012; Tao et al., 2012; Waycott et al., 2013) which could be indicative of first year or trial and error adoptions. Others considered the need for iterations of implementation (Haines, 2015) and strategies to minimise these impacts (Waycott et al., 2013; Zdravkova, Ivanović, \& Putnik, 2012).

\section{Workload efficiencies - time savings}

One expected outcome of implementing TfA is the potential to reduce staff workload (see Table 4), such as reducing time on assessment tasks and facilitating better use of class time. This is most apparent with online quizzes, in particular MCQs. MCQs and online quizzes are the most common efficiency-focused use of TfA, particularly in large classes (Bennett et al., 2017). Within these systems students' work is machine assessed, sometimes aligned to automated feedback, and sometimes with redirection to content, thereby reducing grading time for academics. Workload efficiencies are mostly evident in systems that incorporate automated feedback. Mechanisms supporting the provision of feedback rather than providing it, such as online marking rubrics and comment banks (Buckley \& Cowap, 2013; Heinrich \& Milne, 2012), or the delivery of generic feedback via video (Crook et al., 2012) were discussed too but not assessed in relation to their potential to improve submissions quality. The use of VLEs to deliver group feedback was seen as timesaving (Bennett et al., 2017), though in Crook et al (2012) they found that group feedback was viewed as an addition to individual feedback and so increased academic staff workload. ePortolios reportedly support and facilitate grading and feedback delivery by being quicker to mark and easier to manage (Almpanis, 2015; Bennett et al., 2017) but can also increase demands from students (Almpanis, 2015).

In some cases, increased workload was encountered at the beginning and implementation stages (Blackburn, 2017; Chew, Ding, \& Rowell, 2015; Mettiäinen, 2015; Rodríguez-Gómez, QuesadaSerra, \& Ibarra-Sáiz, 2016; Wanner \& Palmer, 2015), but in other cases the increased workload persisted as long as students are engaging with the TfA tool (Gray et al., 2012; Lafuente Martínez et al., 2015; Waycott et al., 2013; Zdravkova et al., 2012). Several studies on Web 2.0Social Media TfA noted increased time and heavier workload associated with managing the assessment grading, at some if not all stages of the process.

\section{Table 4 Studies with TfA tools impacting on workload-time}

\section{Tools $\quad$ Studies}

MCQs - Online Quizzes

Bennett et al. (2017); Bogarra Rodriguez, Corbalan Fuertes, Font Piera, Plaza Garcia, and Arcega Solsona (2012); Chao et al. (2012); Chen et 
al. (2013); Flosason et al. (2015); Griff and Matter (2013); Hsiao et al. (2016); Kim (2015); Malau-Aduli, Assenheimer, Choi-Lundberg, and Zimitat (2014); McNeill et al. (2012); Mettiäinen (2015); Mora, Sancho-Bru, Iserte, and Sánchez (2012); Nguyen, Hui, and Fong (2013); Schaffer, Young, Ligon, and Chapman (2017); Sullivan (2016); Sweeney et al. (2017); Whitworth and Wright (2015)

Automated feedback

Achumba, Azzi, Dunn, and Chukwudebe (2013); Blackburn (2017);

Buckley and Cowap (2013); Caminero et al. (2016); Heinrich and Milne (2012); Kim (2015); Kuikka, Kitola, and Laakso (2014); Link, Dursun, Karakaya, and Hegelheimer (2014); Mora et al. (2012); Pittenger and Olson-Kellogg (2012); Whitelock et al. (2015)

Web 2.0-Social Media

Caple and Bogle (2013); Goldstein and Peled (2016); Gray et al. (2012); Lafuente Martínez et al. (2015); Mettiäinen (2015); RodríguezGómez et al. (2016); Wanner and Palmer (2015); Waycott et al. (2013); Zdravkova et al. (2012)

\section{Transparency and Visibility - Student Work}

There was an aspirational sense that efficiencies may be generated through enhanced ability of academic staff to monitor student activity (Caminero et al., 2016; Flosason et al., 2015; Lafuente Martínez et al., 2015; Zou, 2013). For example, in class Clicker use allowed engagement with and understanding of the coursework (Flosason et al., 2015) and before class polling was suggested to allow for a better prepared student (Sun, Martinez, \& Seli, 2014). There was findings from two studies that student activity visibility and monitoring in a VLE improved the academics potential to diagnose and deal with students' problems more efficiently, though with academic staff time implications (Caminero et al., 2016; Lafuente Martínez et al., 2015).

When visibility is within a public space, for example via Web 2.0-Social Media tools, there were different challenges. These TfA were introduced predominantly with the pedagogical goal (often not explicitly mentioned) to facilitate collaborative learning practices (Gray et al., 2012; McNeill et al., 2012; Waycott et al., 2013). Though this goal was achieved, it was at times marred by a significant increase in workload to monitor, manage and respond in a timely manner to online open content for assessment. Various studies found that this workload could be overwhelming for academic staff (Caple \& Bogle, 2013; Gray et al., 2012; Lafuente Martínez et al., 2015; Wanner \& Palmer, 2015; Waycott et al., 2013; Zheng et al., 2015). There were also plagiarism and governance issues for academic staff (student netiquette) with this type of visibility (Waycott et al., 2013).

\section{Summary}

The findings for the systematic review demonstrate that multiple technology tools afford enhancements to staff efficiencies but with the caveat that they may also increase workload via student demands or needs to moderate and monitor student work on an on-going basis. 


\section{Institutional Environment and Support}

What types of institutional environment and support do institutions need to provide to develop technology enhanced (i.e. pedagogically grounded) Assessment OF/FOR/AS Learning?

A number of papers in the systematic review discussed institutional leadership and support through policies focusing on specific issues in TfA such as plagiarism (Akçapınar, 2015), to broader policies that develop academic supports (Mettiäinen, 2015; Whitelock et al., 2015) or communities of practice (Blackburn, 2017; Marín et al., 2016). Papers by Blackburn (2017) and Cochrane et al (2013) discussed creating a role to support sustainable TfA implementation. These papers emphasise how institutional leadership and support through policies and resource allocation can facilitate the sustainability of TfA.

Institutional financial investment to support TfA seems necessary. However, the papers do not provide cost benefit analyses. For example, Schaffer et al (2017) make an argument that the fixed cost of TfA implementation provides economies of scale for very large student cohorts, however this claim is not evaluated in the paper. Some studies list required resources (Chao et al., 2012; Crook et al., 2012; Hutchings \& Quinney, 2015; Summers et al., 2014) however they do not elaborate on costs. Bennett et al (2017) found that cost, particularly unanticipated costs, was a common barrier to adoption of TfA. Blackburn found "central strategic funding" as a "critical component" in their implementation (2017, p. 161). These papers emphasise the need for resourcing that is aligned with clear institutional policies regarding technology and teaching and learning.

The need for financial investment in appropriate infrastructure for TfA was exemplified. Integrating systems that facilitate ease of use emerged as a key consideration in adoption of TfA for academic staff, more so than available functionality (Heinrich \& Milne, 2012; Kuikka et al., 2014; Rubin et al., 2013). Another key consideration was integration with existing learning management systems (LMS) (Caminero et al., 2016; Kuikka et al., 2014; Wang, Doll, Deng, Park, \& Yang, 2013). In addition to ease of use and integration, Wang et al (2013) suggest that integration of principles of good teaching are influenced by the re-configurability of LMS systems. These papers stress the complex interaction of factors that influence sustained technology adoption and how these must be considered in infrastructure decisions.

\section{Table 5 Training approaches in studies}

\begin{tabular}{|ll|}
\hline $\begin{array}{l}\text { Approaches to Training } \\
\text { Time for staff training and CPD }\end{array}$ & Studies \\
& Bogarra Rodriguez et al. (2012); Buckley and \\
& Cowap (2013); Carruthers et al. (2015); Chew et \\
& al. (2015); Kuikka et al. (2014); McNeill et al. \\
& (2012); Mettiäinen (2015); Penketh and Beaumont \\
& (2014); Zou (2013) \\
\hline Training for students as well as staff & $\begin{array}{l}\text { Bennett et al. (2017); Bogarra Rodriguez et al. } \\
\text { (2012); Buckley and Cowap (2013); Carruthers et }\end{array}$ \\
& $\begin{array}{l}\text { al. (2015); Chew et al. (2015); Penketh and } \\
\text { Beaumont (2014) }\end{array}$ \\
\hline Aligned with technology and pedagogy & Heinrich and Milne (2012); Kuikka et al. (2014); \\
\hline
\end{tabular}


Meadows et al. (2016); Schoonenboom (2012); Steenbergen-Hu and Cooper (2014); Wimpenny, Savin-Baden, Mawer, Steils, and Tombs (2012); Zou (2013)

The provision of high quality training was identified in several papers as necessary for introducing and sustaining the use of TfA, see Table 5. Many of the studies highlight the need to provide support, time, training and continuing professional development (CPD) to academic staff as they learn to integrate and use any new TfA system. The necessity of training and supporting not only academic staff, but also students, in the use of TfA is also emphasised in many studies, see Table 6. Regarding academic staff training, the papers suggest that training should be context-sensitive (Buckley \& Cowap, 2013), integrate and align technology and pedagogy, and be embedded with the course and institutional structures (Zou, 2013). In addition to these requirements, it was noted that training should also explicitly target a deeper understanding of the affordances of technologies to develop curriculum goals (McNeill et al., 2012) as well as tensions between pedagogy and technological affordances (Buus, 2012; Haines, 2015). Bennett et al (2017) also note that development of the training infrastructure needs to consider and actively target barriers created by the knowledge and communications gap between technical and academic staff. This builds on the points regarding institutional leadership and the creation of posts to specifically target the intersection between technology and subject-specific pedagogy.

The effectiveness of training in several studies is questionable, with findings of non-attendance and/or subsequent to attendance, limited adoption of technology (Buus, 2012; Mettiäinen, 2015) or short-term adoption only (Tao et al., 2012). Even in the case of highly committed and welltrained academic staff, on-going challenges to sustained adoption of technology occurred (Haines, 2015). This would suggest that training is not the only solution to this complex issue.

Furthermore, many of the studies strongly emphasise the need for appropriate allocations of time to facilitate TEA, for set up and implementation (Blair et al., 2016; Whitworth \& Wright, 2015), training and development for both academic staff and students (Çakiroglu et al., 2016), maintenance, upkeep and up skilling and learning design iterations (Marín et al., 2016; Summers et al., 2014; Zheng et al., 2015).

\section{Summary}

This synthesis of findings did not provide clear guidelines in relation to the required institutional environment and supports like institutional leadership, resourcing, and context-sensitive, timely training. The findings highlighted a complex interplay of challenges both during initial set up and the on-going support needed in terms of time, resources and training. This aligns with the broader literature on changing practice in education (Maughan, Teeman, \& Wilson, 2012).

\section{Future Research Direction, Limitations, and Policy Implications}

This systematic review supports the current state of the field, which has emphasised a scarcity of studies which investigate the core issues relating to academic staff technological adoption within teaching and learning in higher education (King \& Boyatt, 2015; Selwyn, 2013) Similarly to 
Heitink et al., (2016) and Bennett et al., (2016) this work emphasises the need for more studies into the required operational costs, time and resources of TfA for academic staff. The systematic review found a lack of any (published) longitudinal investigation of academic staff experiences of implementing or using TfA in a sustained manner. There is a need for more studies that have external validity, and show clearly the reproduction of benefits in multiple settings and over time. Despite benefits for students demonstrated in the extant studies (see for example Nikou and Economides, 2018), these findings highlight the preponderance of small-scale case studies by self-motivated innovators/early adopters. Sufficient studies of effective enduring integration of educational technologies by academics are not yet in evidence. Thus there is a need to scale up research approaches into the value and effectiveness of adoption of TfA for all stakeholders in the process sustained over time in longitudinal studies.

Few papers were situated within an identified theoretical framework pertaining to assessment, digital technology, pedagogy, or adoption. An examination of the sustained adoption of technology by academic staff requires a deep engagement with educator cognition and knowledge (Fung \& Gordon, 2016), "understanding what teachers think, know and believe" (Borg, 2003, p. 81). Also notable is the need for models of professional development that support adaptive change to practice which may entail challenges to belief systems (Heifetz, Grashow, \& Linsky, 2009). These considerations are largely absent in the current research on TfA.

Similar to (Bennett et al, 2017) we found that in terms of introducing TfA, the goal of achieving efficiencies often came first for educators and institutions before consideration of pedagogy or the learning environment and associated supports. Regarding policy, there is a clear need for professional development supports and institutional policies, which acknowledge and address these challenges and provide leadership to underpin sustained adoption and use of TfA (King \& Boyatt, 2015). The challenge is to move beyond where we are now to where we could be. As Bennett et al noted, many TfA currently in use are "pedagogically satisfactory rather than optimal" (2017, p. 679). The lack of theoretical guidance, reflected in the absence of the integration of technology deployment theories into either educational frameworks, assessment or learning processes, are areas where further consideration could offer significant benefits to both practice and future research.

\section{Conclusion}

This study shows that TfA is still at an early stage of adoption with limited pedagogical underpinnings or theoretical frameworks. Critically even though discussion of academic staff efficiencies was dominant, there was a lack of quantification in terms of design, set-up and ongoing maintenance, time and resource costs or gains. Despite a sense that institutional supports could be critical, there was limited insight into the type or scale of resources and institutional structures that could best support and drive adoption.

To evaluate the effectiveness and sustainability of TfA by academic staff beyond the aspirational we suggest that the complexity of the challenges and changes required to sustain TfA, across multiple technologies and assessment types must be underpinned by sound pedagogy and educational theory supported by more rigorous and particularly longitudinal empirical research. 


\section{Statements on open data, ethics and conflict of interest}

We declare that any data will be available through direct application to the first author. We declare that no human participants were used in this study. We declare no conflicts of interest regarding the reported study.

\section{References}

Achumba, E. I., Azzi, D., Dunn, L. V., \& Chukwudebe, A. G. (2013). Intelligent Performance Assessment of Students' Laboratory Work in a Virtual Electronic Laboratory Environment. IEEE Transactions on Learning Technologies, 6(2), 103-116.

Akçapınar, G. (2015). How automated feedback through text mining changes plagiaristic behavior in online assignments. Computers \& Education, 87, 123-130. doi:10.1016/j.compedu.2015.04.007

Almpanis, T. (2015). Staff Development and Institutional Support for Technology Enhanced Learning in UK Universities. Electronic Journal of e-Learning, 13(5), 366-375.

Bennett, S., Dawson, P., Bearman, M., Molloy, E., \& Boud, D. (2017). How technology shapes assessment design: Findings from a study of university teachers. British Journal of Educational Technology, 48(2), 672-682. doi:10.1111/bjet.12439

Black, P. (2008). Formative assessment in the learning and teaching of design and technology. Design and Technology Education: An International Journal, 13(3).

Black, P., Harrison, C., Lee, C., Marshall, B., \& Wiliam, D. (2004). Working inside the Black Box: Assessment for Learning in the Classroom. Phi Delta Kappan, 86(1).

Blackburn, G. (2017). A university's strategic adoption process of an PBL-aligned eLearning environment: an exploratory case study. Educational Technology Research \& Development, 65(1), 147-176. doi:10.1007/s11423-016-9472-3

Blair, E., Maharaj, C., \& Primus, S. (2016). Performance and perception in the flipped classroom. Education and Information Technologies, 21(6), 1465-1482. doi:10.1007/s10639-015-9393-5

Bogarra Rodriguez, S., Corbalan Fuertes, M., Font Piera, A., Plaza Garcia, I., \& Arcega Solsona, F. J. (2012). Lessons Learned in the Use of WIRIS Quizzes to Upgrade Moodle to Solve Electrical Circuits. IEEE Transactions on Education, 55(3), 412-417. doi:10.1109/TE.2011.2181381

Borg, S. (2003). Teacher cognition in language teaching: A review of research on what language teachers think, know, believe, and do. Language Teaching, 36(2), 81-109.

Buckley, E., \& Cowap, L. (2013). An evaluation of the use of Turnitin for electronic submission and marking and as a formative feedback tool from an educator's perspective. British Journal of Educational Technology, 44(4), 562-570. doi:10.1111/bjet.12054

Buus, L. (2012). Scaffolding Teachers Integrate Social Media into a Problem-Based Learning Approach? Electronic Journal of e-Learning, 10(1), 13-22.

Çakiroglu, Ü., Kokoç, M., Kol, E., \& Turan, E. (2016). Exploring Teaching Programming Online through Web Conferencing System: The Lens of Activity Theory. Educational Technology \& Society, 19(4), 126-139.

Caminero, A. C., Ros, S., Hernández, R., Robles-Gómez, A., Tobarra, L., \& Granjo, P. J. T. (2016). VirTUal remoTe labORatories Management System (TUTORES): Using Cloud Computing to Acquire University Practical Skills. IEEE Transactions on Learning Technologies, 9(2), 133-145. doi:10.1109/TLT.2015.2470683

Caple, H., \& Bogle, M. (2013). Making Group Assessment Transparent: What Wikis Can Contribute to Collaborative Projects. Assessment \& Evaluation in Higher Education, 38(2), 198-210. 
Carruthers, C., McCarron, B., Bolan, P., Devine, A., McMahon-Beattie, U., \& Burns, A. (2015). "I Like the Sound of That"--An Evaluation of Providing Audio Feedback via the Virtual Learning Environment for Summative Assessment. Assessment \& Evaluation in Higher Education, 40(3), 352-370.

Chao, K. J., Hung, I. C., \& Chen, N. S. (2012). On the Design of Online Synchronous Assessments in a Synchronous Cyber Classroom. Journal of Computer Assisted Learning, 28(4), 379-395.

Chen, N. S., Wei, C. W., Huang, Y. C., \& Kinshuk. (2013). The integration of print and digital content for providing learners with constructive feedback using smartphones. British Journal of Educational Technology, 44(5), 837-845. doi:10.1111/j.1467-8535.2012.01371.x

Chew, E., Ding, S. L., \& Rowell, G. (2015). Changing attitudes in learning and assessment: Cast-off 'plagiarism detection' and cast-on self-service assessment for learning. Innovations in Education and Teaching International, 52(5), 454-463. doi:10.1080/14703297.2013.832633

Cochrane, T., Sissons, H., Mulrennan, D., \& Pamatatau, R. (2013). Journalism 2.0: Exploring the Impact of Mobile and Social Media on Journalism Education. International Journal of Mobile and Blended Learning, 5(2), 22-38.

Crook, A., Mauchline, A., Maw, S., Lawson, C., Drinkwater, R., Lundqvist, K., . . Park, J. (2012). The Use of Video Technology for Providing Feedback to Students: Can It Enhance the Feedback Experience for Staff and Students? Computers \& Education, 58(1), 386-396.

Dawson, P., \& Henderson, M. (2017). How Does Technology Enable Scaling Up Assessment for Learning? In D. Carless, S. Bridges, C. Ka Yuk Chan, \& R. Glofcheski (Eds.), Scaling up Assessment for Learning in Higher Education (pp. 209-222). Singapore: Springer.

Daly, C., Pachler, N., Mor, Y., \& Mellar, H. (2010). Exploring Formative E-Assessment: Using Case Stories and Design Patterns. Assessment \& Evaluation in Higher Education, 35(5), 619-636

Deeley, S. J. (2018). Using technology to facilitate effective assessment for learning and feedback in higher education. Assessment \& Evaluation in Higher Education, 43(3), 439-448.

Earl, L. M. (2013). Assessment As Learning: Using Classroom Assessment to Maximize Student Learning. Thousand Oaks, CA: Corwin Press.

EPPI Centre. (2017). EPPI-Reviewer 4: Software for Systematic Reviews. Retrieved from http://eppi.ioe.ac.uk/eppireviewer4/eppireviewer4.aspx

Flosason, T. O., McGee, H. M., \& Diener-Ludwig, L. (2015). Evaluating Impact of Small-Group Discussion on Learning Utilizing a Classroom Response System. Journal of Behavioral Education, 24(3), 317-337.

Fung, D., \& Gordon, C. (2016). Rewarding educators and education leaders in research-intensive universities. York, UK.: Higher Education Academy.

Goldstein, O., \& Peled, Y. (2016). Pedagogical Aspects of Integrating Wikis in Pre-Service Teacher Education. Technology, Pedagogy and Education, 25(4), 469-486.

Gough, D., Oliver, S., \& Thomas, J. (2012). An Introduction to Systematic Reviews. London: Sage.

Gray, K., Waycott, J., Clerehan, R., Hamilton, M., Richardson, J., Sheard, J., \& Thompson, C. (2012). Worth it? Findings from a study of how academics assess students' Web 2.0 activities. Research in Learning Technology, 20(1), 1-15. doi:10.3402/rlt.v20i0.16153

Griff, E. R., \& Matter, S. F. (2013). Evaluation of an adaptive online learning system. British Journal of Educational Technology, 44(1), 170-176. doi:10.1111/j.1467-8535.2012.01300.x

Habib, L., \& Johannesen, M. (2014). Perspectives on academic staff involvement in the acquisition and implementation of educational technologies. Teaching in Higher Education, 19(5), 484-496.

Haines, K. J. (2015). Learning to Identify and Actualize Affordances in a New Tool. Language Learning \& Technology, 19(1), 165-180.

Harden, A., \& Gough, D. (2012). Quality and relevance appraisal. In D. Gough, S. Oliver, \& J. Thomas (Eds.), An Introduction to Systematic Reviews (pp. 153-178). London: Sage.

Heifetz, R. A., Grashow, A., \& Linsky, M. (2009). The practice of adaptive leadership: Tools and tactics for changing your organization and the world. Boston, MA: Harvard Business Press. 
Heinrich, E., \& Milne, J. (2012). Applying a Framework to Evaluate Assignment Marking Software: A Case Study on Lightwork. Research in Learning Technology, 20(2), 14.

Heitink, M. C., Van der Kleij, F. M., Veldkamp, B. P., Schildkamp, K., \& Kippers, W. B. (2016). A systematic review of prerequisites for implementing assessment for learning in classroom practice. Educational Research Review, 17(February, 2016), 50-62.

Higgins, J. P. T., \& Green, S. (2011). Cochrane Handbook for Systematic Reviews of Interventions (J. P. T. Higgins \& S. Green Eds. Vol. Version 5.1.0): The Cochrane Collaboration.

Hsiao, H.-S., Chang, C.-S., Lin, C.-Y., Chen, B., Wu, C.-H., \& Lin, C.-Y. (2016). The Development and Evaluation of Listening and Speaking Diagnosis and Remedial Teaching System. British Journal of Educational Technology, 47(2), 372-389.

Hutchings, M., \& Quinney, A. (2015). The Flipped Classroom, Disruptive Pedagogies, Enabling Technologies and Wicked Problems: Responding to "The Bomb in the Basement". Electronic Journal of e-Learning, 13(2), 106-119.

JISC. (2010). Effective Assessment in a Digital Age. Retrieved from https://www.webarchive.org.uk/wayback/archive/20140614115719/http://www.jisc.ac.uk/media/ documents/programmes/elearning/digiassass_eada.pdf

Keane, M., Sutton, M., Farragher, L., \& Long, J. (2016). Barriers and facilitators to successful hospital mergers: A systematic review. Retrieved from Dublin: http://www.hrb.ie/uploads/tx hrbpublications/Barriers and facilitators to successful hospital mergers.pdf

Kim, J.-Y. (2015). A study of perceptional typologies on computer based assessment (CBA): Instructor and student perspectives. Journal of Educational Technology \& Society, 18(2), 80-96.

King, E., \& Boyatt, R. (2015). Exploring factors that influence adoption of e-learning within higher education. British Journal of Educational Technology, 46(6), 1272-1280.

Kirkwood, A., \& Price, L. (2013). Missing: evidence of a scholarly approach to teaching and learning with technology in higher education. Teaching in Higher Education, 18(3), 327-337.

Kuikka, M., Kitola, M., \& Laakso, M.-J. (2014). Challenges when introducing electronic exam. Research in Learning Technology, 22. doi:10.3402/rlt.v22.22817

Lafuente Martínez, M., Álvarez Valdivia, I. M., \& Remesal Ortiz, A. (2015). Making Learning More Visible through E-Assessment: Implications for Feedback. Journal of Computing in Higher Education, 27(1), 10-27.

Link, S., Dursun, A., Karakaya, K., \& Hegelheimer, V. (2014). Towards Better ESL Practices for Implementing Automated Writing Evaluation. CALICO Journal, 31(3).

Liou, W.-K., Bhagat, K. K., \& Chang, C.-Y. (2016). Beyond the Flipped Classroom: A Highly Interactive Cloud-Classroom (HIC) Embedded into Basic Materials Science Courses. Journal of Science Education and Technology, 25(3), 460-473.

Maher, B., Drachsler, H., Kalz, M., Hoare, C., Sorensen, H., Lezcano, L., . . Specht, M. (2013). Use of Mobile Applications for Hospital Discharge Letters: Improving Handover at Point of Practice. International Journal of Mobile and Blended Learning, 5(4), 19-42.

Malau-Aduli, B. S., Assenheimer, D., Choi-Lundberg, D., \& Zimitat, C. (2014). Using computer-based technology to improve feedback to staff and students on MCQ assessments. Innovations in Education \& Teaching International, 51(5), 510-522. doi:10.1080/14703297.2013.796711

Manca, S., Grion, V., Armellini, A., \& Devecchi, C. (2017). Editorial: Student Voice. Listening to Students to Improve Education through Digital Technologies. British Journal of Educational Technology, 48(5), 1075-1080.

Marín, V. I., Jääskelä, P., Häkkinen, P., Juntunen, M., Rasku-Puttonen, H., \& Vesisenaho, M. (2016). Seamless Learning Environments in Higher Education with Mobile Devices and Examples. International Journal of Mobile and Blended Learning, 8(1), 51-68.

Maughan, S., Teeman, D., \& Wilson, R. (2012). What leads to positive change in teaching practice? (NFER Research Programme: Developing the Education Workforce). Retrieved from NFER: Slough: https://www.nfer.ac.uk/publications/RCTL01/RCTL01.pdf 
McMaster University. (2016). Quality Assessment Tool - Review Articles. Retrieved from https://www.healthevidence.org/documents/our-appraisaltools/QATool\&Dictionary_01Jun16.pdf

McNeill, M., Gosper, M., \& Xu, J. (2012). Assessment choices to target higher order learning outcomes: The power of academic empowerment. Research in Learning Technology, 20(3), 283-296. doi:10.3402/rlt.v20i0.17595

Meadows, C., Soper, K., Cullen, R., Wasiuk, C., McAllister-Gibson, C., \& Danby, P. (2016). Shaping the future of learning using the student voice: We're listening but are we hearing clearly? Research in Learning Technology, 24. doi:10.3402/rlt.v24.30146

Mettiäinen, S. (2015). Electronic Assessment and Feedback Tool in Supervision of Nursing Students during Clinical Training. Electronic Journal of e-Learning, 13(1), 42-56.

Moher, D., Liberati, A., Tetzlaff, J., \& Altman, D. G. (2009). Preferred reporting items for systematic reviews and meta-analyses: the PRISMA statement. BMJ, 339. doi:10.1136/bmj.b2535

Mora, M. C., Sancho-Bru, J. L., Iserte, J. L., \& Sánchez, F. T. (2012). An e-assessment approach for evaluation in engineering overcrowded groups. Computers \& Education, 59(2), 732-740. doi:10.1016/j.compedu.2012.03.011

Neely, P., \& Tucker, J. (2013). Case study: An examination of the decision making process for selecting simulations for an online MBA program. Education \& Training, 55(2), 128-138. doi:10.1108/00400911311304788

Nguyen, L. M., Hui, S. C., \& Fong, C. A. (2013). Large-Scale Multiobjective Static Test Generation for Web-Based Testing with Integer Programming. IEEE Transactions on Learning Technologies, 6(1), 46-59.

Nikou, S. A. \& Economides, A. (2018) Mobile-based assessment: A literature review of publications in major referred journals from 2009 to 2018, Computers \& Education, 125, Pages 101-119

Onrubia, J., \& Engel, A. (2012). The Role of Teacher Assistance on the Effects of a Macro-Script in Collaborative Writing Tasks. International Journal of Computer-Supported Collaborative Learning, 7(1), 161-186.

Paiva, J., Morais, C., Costa, L., \& Pinheiro, A. (2017). The shift from "e-learning" to "learning": Invisible technology and the dropping of the "e". British Journal of Educational Technology, 47(2), 226238.

Penketh, C., \& Beaumont, C. (2014). 'Turnitin said it wasn't happy': can the regulatory discourse of plagiarism detection operate as a change artefact for writing development? Innovations in Education \& Teaching International, 51(1), 95-104. doi:10.1080/14703297.2013.796721

Pittenger, A. L., \& Olson-Kellogg, B. (2012). Leveraging Learning Technologies for Collaborative Writing in an Online Pharmacotherapy Course. Distance Education, 33(1), 61-80.

Rodríguez-Gómez, G., Quesada-Serra, V., \& Ibarra-Sáiz, M. S. (2016). Learning-oriented e-assessment: the effects of a training and guidance programme on lecturers' perceptions. Assessment \& Evaluation in Higher Education, 41(1), 35-52. doi:10.1080/02602938.2014.979132

Rubin, B., Fernandes, R., \& Avgerinou, M. D. (2013). The Effects of Technology on the Community of Inquiry and Satisfaction with Online Courses. Internet and Higher Education, 17, 48-57.

Schaffer, H. E., Young, K. R., Ligon, E. W., \& Chapman, D. D. (2017). Automating Individualized Formative Feedback in Large Classes Based on a Directed Concept Graph. Frontiers in Psychology, 8, 1-11. doi:10.3389/fpsyg.2017.00260

Schoonenboom, J. (2012). The Use of Technology as One of the Possible Means of Performing Instructor Tasks: Putting Technology Acceptance in Context. Computers \& Education, 59(4), 1309-1316.

SCImago. (2007). SJR - SCImago Journal \& Country Rank. Retrieved from http://www.scimagojr.com Selwyn, N. (2013). Digital technology and the contemporary university: on some research issues. Distances et médiations des savoirs, 4. 
Spector, J.M. Ifenthaler, D. Samspon, D. Yang, L. Mukama, E. Warusavitarana A., (2016). Technology enhanced formative assessment for 21st century learning, Educational Technology \& Society, 19 (3) (2016), pp. 58-71

Steenbergen-Hu, S., \& Cooper, H. (2014). A meta-analysis of the effectiveness of intelligent tutoring systems on college students' academic learning. Journal of Educational Psychology, 106(2), 331347. doi:10.1037/a0034752

Sullivan, D. P. (2016). An Integrated Approach to Preempt Cheating on Asynchronous, Objective, Online Assessments in Graduate Business Classes. Online Learning, 20(3), 195-209.

Summers, M. T., Robinson, K. D., \& Timmons, R. J. (2014). Beyond the On-Campus Humanities Learning Experience: A Case Study in Utilizing Assessment Tools in an Online Dance Studies Course. Interdisciplinary Humanities, 31(Spring 2014), 72-80.

Sun, J. C.-Y., Martinez, B., \& Seli, H. (2014). Just-in-time or plenty-of-time teaching? Different electronic feedback devices and their effect on student engagement. Journal of Educational Technology \& Society, 17(2), 234-244.

Sweeney, T., West, D., Groessler, A., Haynie, A., Higgs, B. M., Macaulay, J.,Yeo, M. (2017). Where's the transformation? Unlocking the potential of technology-enhanced assessment. Teaching \& Learning Inquiry, 5(1), 1-18.

Tao, Y.-H., Cheng, C.-J., \& Sun, S.-Y. (2012). Alignment of Teacher and Student Perceptions on the Continued Use of Business Simulation Games. Educational Technology \& Society, 15(3), 177 189.

Wang, J., Doll, W. J., Deng, X., Park, K., \& Yang, M. G. (2013). The Impact of Faculty Perceived Reconfigurability of Learning Management Systems on Effective Teaching Practices. Computers \& Education, 61, 146-157.

Wanner, T., \& Palmer, E. (2015). Personalising learning: Exploring student and teacher perceptions about flexible learning and assessment in a flipped university course. Computers \& Education, 88, 354369. doi:10.1016/j.compedu.2015.07.008

Waycott, J., Sheard, J., Thompson, C., \& Clerehan, R. (2013). Making students' work visible on the social web: A blessing or a curse? Computers \& Education, 68, 86-95. doi:10.1016/j.compedu.2013.04.026

Whitelock, D., Thorpe, M., \& Galley, R. (2015). Student workload: A case study of its significance, evaluation and management at the Open University. Distance Education, 36(2), 161-176. doi:10.1080/01587919.2015.1055059

Whitworth, D. E., \& Wright, K. (2015). Online assessment of learning and engagement in university laboratory practicals. British Journal of Educational Technology, 46(6), 1201-1213. doi:10.1111/bjet.12193

Wimpenny, K., Savin-Baden, M., Mawer, M., Steils, N., \& Tombs, G. (2012). Unpacking Frames of Reference to Inform the Design of Virtual World Learning in Higher Education. Australasian Journal of Educational Technology, 28(3), 24.

Zdravkova, K., Ivanović, M., \& Putnik, Z. (2012). Experience of integrating web 2.0 technologies. Educational Technology Research \& Development, 60(2), 361-381. doi:10.1007/s11423-0119228-z

Zheng, B., Niiya, M., \& Warschauer, M. (2015). Wikis and Collaborative Learning in Higher Education. Technology, Pedagogy and Education, 24(3), 357-374.

Zou, B. (2013). Teachers' Support in Using Computers for Developing Students' Listening and Speaking Skills in Pre-Sessional English Courses. Computer Assisted Language Learning, 26(1), 83-99. 


\section{Supporting Information}

Additional supporting information may be found online in the supporting information tab for this article.

Table S1: Summary of studies included in the systematic review.

S2: Quality Assessment Tools Used in Systematic Review 